\title{
Evaluation of Contamination of Hands of the Medical Students in a Medical Teaching Tertiary Care Hospital
}

\author{
Keshvi Chauhan'1, Summaiya Mullan² \\ ${ }^{1}$ Government Medical College, Surat, India \\ ${ }^{2}$ Department of Microbiology, Government Medical College, Surat, India \\ Email: keshvichauhan@gmail.com, mullasummaiya@gmail.com
}

How to cite this paper: Chauhan, K. and Mullan, S. (2017) Evaluation of Contamination of Hands of the Medical Students in a Medical Teaching Tertiary Care Hospital. Advances in Microbiology, 7, 666-671. https://doi.org/10.4236/aim.2017.79052

Received: August 11, 2017

Accepted: September 19, 2017

Published: September 22, 2017

Copyright $\odot 2017$ by authors and Scientific Research Publishing Inc. This work is licensed under the Creative Commons Attribution International License (CC BY 4.0).

http://creativecommons.org/licenses/by/4.0/

\begin{abstract}
Background: In the hospital, patients are often exposed to multiple procedures, invasive devices etc., increasing their chances of contracting such potential pathogens. Most of the time these potential pathogens exhibit multiple drug resistance. Aim: In view of the above factors, this study was undertaken to determine the rate of colonization of potential bacterial pathogens in the hands of final year MBBS undergraduate students. As per their clinical teaching curriculum, they visit the wards/ICU/OT, etc. on a daily basis. Method: Samples were collected from the hands of final year MBBS undergraduate students. The samples were collected by rubbing a saline wet swab stick onto the hands of the students and were inoculated onto nutrient agar plates for 18 - 24 hours at $37^{\circ} \mathrm{C}$ aerobically. Bacterial isolates were identified till species level by performing gram staining and biochemical reactions. Antibiotic susceptibility testing was done by Kirby-baur disc diffusion method as per CLSI guidelines 2016. Conclusion: 103 samples were collected from hands of final year undergraduate MBBS students by swab culture method. 38 showed growth and 65 showed no growth. Out of 38 isolates, 36 were Gram positive cocci and 2 were Gram positive bacilli. No Gram negative bacilli were isolated. Amongst 36 Gram positive cocci, 16 were coagulase positive Staphylococcus aureus and 20 were Coagulase negative Staphylococci (CoNS). 14 Staphylococcus aureus out of 16 were methicillin sensitive and 2 were methicillin resistant Staphylococcus aureus (MRSA). Out of 16 Staphylococcus aureus, 1 isolate showed Inducible Clindamycin Resistance (iMLS $S_{B}$ phenotype) and 6 isolates showed complete resistance to erythromycin and clindamycin (constitutive $\mathrm{MLS}_{\mathrm{B}}$ phenotype). 1 Staphylococcus aureus which was Inducible Clindamycin Resistance (iMLS ${ }_{B}$ phenotype) was also methicillin resistant.
\end{abstract}




\section{Keywords}

Medical Students, Hand Samples, Bacterial Culture, MRSA, ICR

\section{Introduction}

Despite the advances in modern sciences, nosocomial infections are a major threat in most of the hospitals and may be as high as 19\% in the developing countries [1], especially in the ICUs and wards, where number of direct contacts between the hands of health care workers (HCW) and the patient occurs, which mandates the strict adherence to infection control practices and standards. The same standards are applicable for the equipment used, as many of the potential pathogens can survive for weeks in the inanimate surfaces. In the hospital, patients are often exposed to multiple procedures, invasive devices etc., increasing their chances of contracting such potential pathogens. Most of the time, these potential pathogens exhibit multiple drug resistance. Multiple Drug Resistant (MDR) organisms are microorganisms (predominately bacteria) resistant to more than one class of microbial agents. Even though MRSA (Methicillin Resistant Staphylococcus aureus) or VRE (Vancomycin Resistant Enterococcus) are resistant to only one class of antimicrobial agents they are frequently associated with resistance to other classes. MRSA is worldwide a major cause for Hospital Acquired Infections (HAI). The prevalence of MRSA ranges from $20 \%-80 \%$ in India [2]. Similarly, among the gram negative bacteria, a major concern is the production of new beta-lactamases which are capable of degrading cephalosporins and carbapenems. Infections with such organisms increase the morbidity, mortality, hospital stay and cost of treatment. Patients are inevitably exposed to higher antibiotics and other drugs which may result in further complications. A reduced HAI rate and good compliance to infection control practices contributes to the reputation of the hospital. In view of the above factors, this study was undertaken to determine the rate of colonization of potential bacterial pathogens in the hands of final year MBBS undergraduate students who are regularly attending the wards, ICUs, OTs, etc. as a part of their clinical teaching curriculum.

\section{Materials and Methods}

Present study was a cross-sectional study which was conducted after the approval from Institution ethics committee. Samples were collected from the hands of final year MBBS undergraduate students as soon as they came back from their daily morning clinical postings. The samples were collected by rubbing a saline wet swab stick onto the hands of the students. First the sample was taken by rubbing the swab on the palmer surfaces of both the hands, followed by finger tips and then the back of hands along with the nail beds and inter-digital space. The collected samples were transported to Clinical Microbiology section of the college, in cold packs immediately within half an hour of collection for aerobic 
bacterial culture and sensitivity. The samples were inoculated onto nutrient agar plates which were appropriately coded. The plates were incubated at $37^{\circ} \mathrm{C}$ aerobically. The plates were checked for growth at the end of 24 hours and 48 hours, and the findings were recorded. The plates which had no growth even after 48 hours were deemed sterile. Those plates which showed growth was further processed to identify the organisms till species level by performing gram staining and appropriate biochemical reactions. Antibiotic susceptibility testing was done by Kirby-baur disc diffusion method as per CLSI guidelines 2016 [3]. In case of Staphylococcus spp MRSA screening was done using Cefoxitin disc $(30 \mu \mathrm{g})$, other antibiotics tested, were erythromycin $(15 \mu \mathrm{g})$, clindamycin $(2 \mu \mathrm{g})$ and azithromycin $(15 \mu \mathrm{g})$. The antibiogram results were interpreted as per CLSI guidelines 2016. Along with detection of Methicillin resistance, D test was also done. A flattening of the zone of inhibition around the Clindamycin disk proximal to the Erythromycin disk (producing a zone of inhibition shaped like the letter D) is considered a positive result and indicates that the Erythromycin has induced Clindamycin resistance (a positive "D-zone test"). For Erythromycin-resistant isolates, induction tests can help laboratories determine whether results for Clindamycin should be reported as susceptible (when the induction test is negative) or as resistant (when the induction test is positive) [4].

\section{Results}

103 samples were taken from hands of final year undergraduate MBBS students by swab culture method. 38 (37\%) showed growth and 65 (63\%) showed no growth (Figure 1). Out of 38 isolates, 36 (95\%) were Gram positive cocci and 2 (5\%) were Gram positive bacilli. No Gram negative bacilli were isolated (Figure 2). Amongst 36 Gram positive cocci isolates, 16 (44\%) were coagulase positive Staphylococcus aureus and 20 (56\%) were Coagulase negative Staphyloccoci (CoNS) (Figure 3). The coagulase positive isolates were checked by fermentation

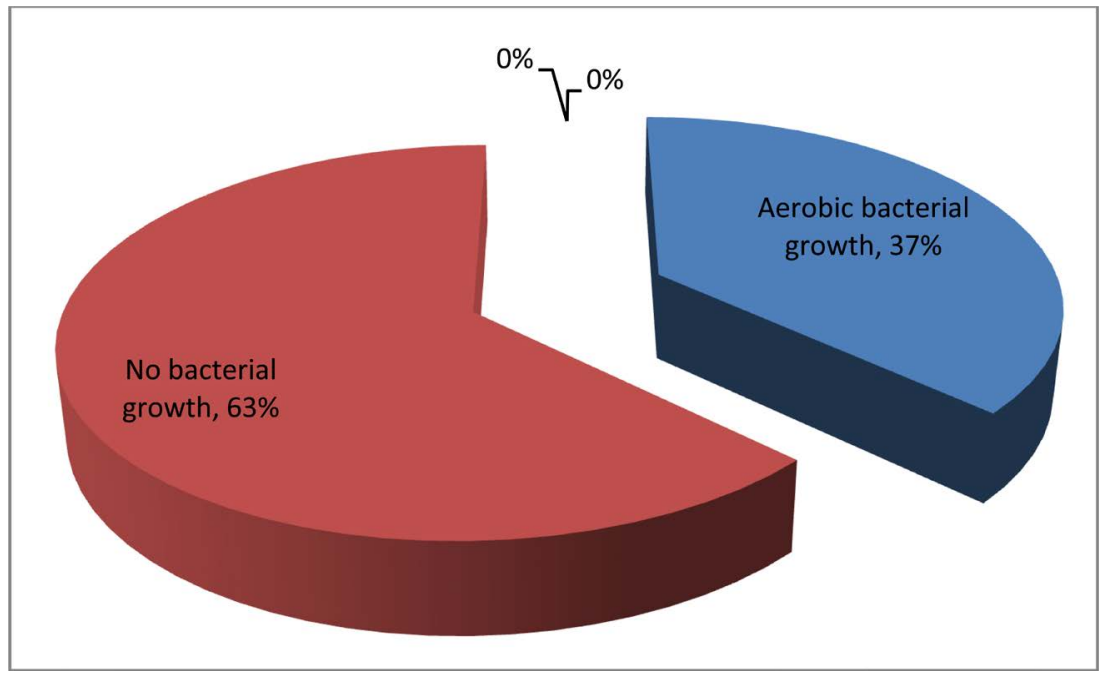

Figure 1. Pie chart showing the percentage of bacterial growth from the samples that were collected from the hands of undergraduate final year MBBS students. 


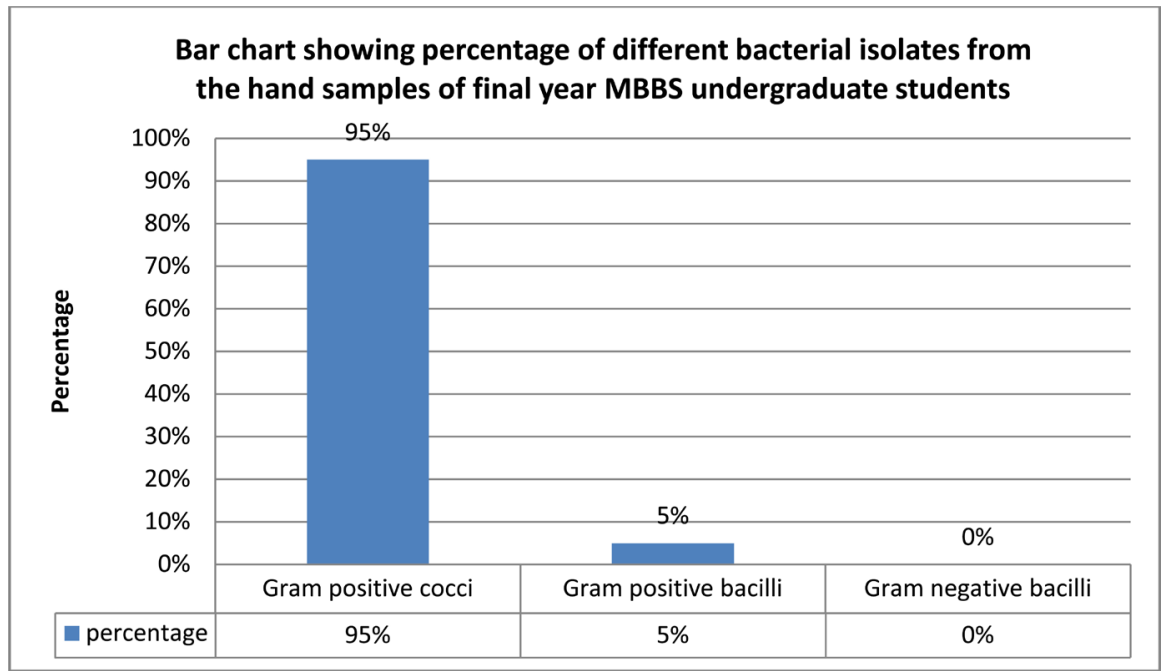

Figure 2. Bar chart showing Gram positive cocci (95\%), Gram positive bacilli (5\%) and Gram negative bacilli (0\%) bacterial isolates from the hand samples of final year MBBS undergraduate students.

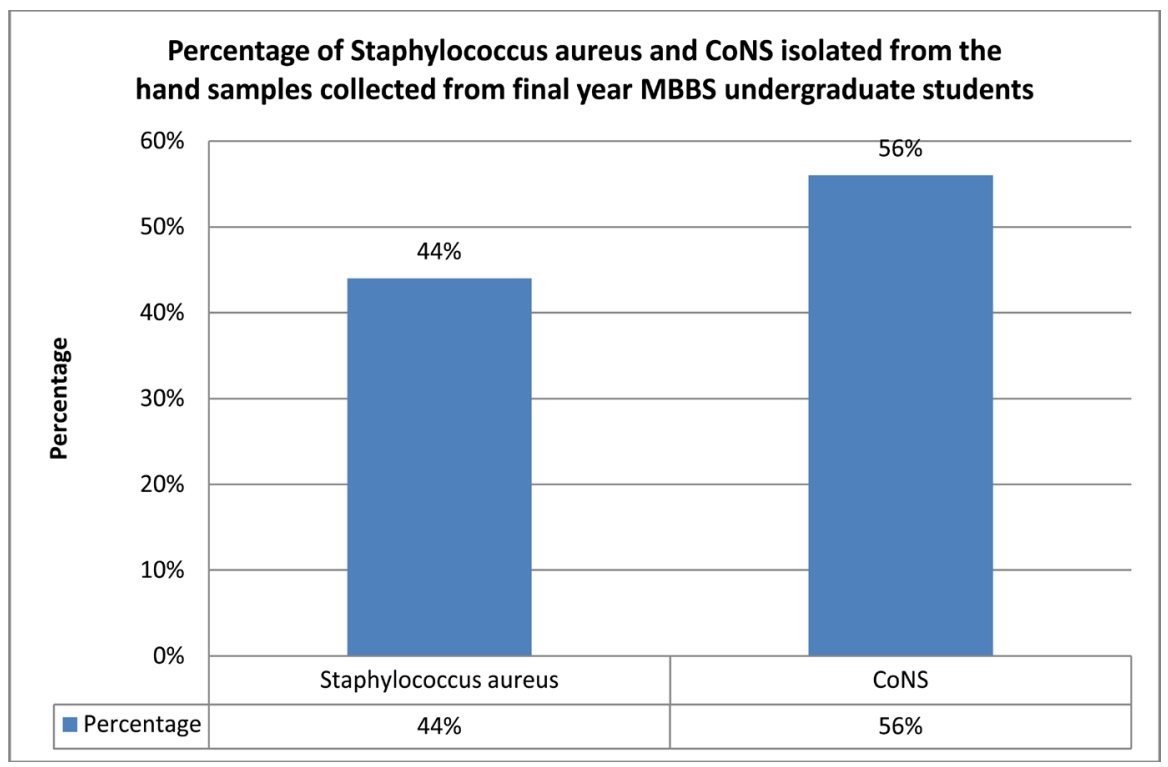

Figure 3. Bar chart showing Staphylococcus aureus (44\%) and CoNS (56\%) from the total Gram positive cocci isolated from the hand samples of final year MBBS undergraduate students.

in MSA (Mannitol Salt Agar). Amongst 20 CoNS, 14 (70\%) were Staphylococcus citrus and 6 (30\%) were Staphylococcus epidermidis.

14 (87\%) Staphylococcus aureus out of 16 were methicillin sensitive and 2 (13\%) were methicillin resistant Staphylococcus aureus (MRSA) (Figure 4). Out of 16 Staphylococcus aureus, 1 (6\%) isolate showed Inducible Clindamycin Resistance (iMLS $\mathrm{B}_{\mathrm{B}}$ phenotype) and $6(38 \%)$ isolates showed complete resistance to erythromycin, clindamycin and azithromycin (constitutive $\mathrm{MLS}_{\mathrm{B}}$ phenotype). 1 (6\%) Staphylococcus aureus which was Inducible Clindamycin Resistance (iMLS $\mathrm{B}_{\mathrm{B}}$ phenotype) was also methicillin resistant. 


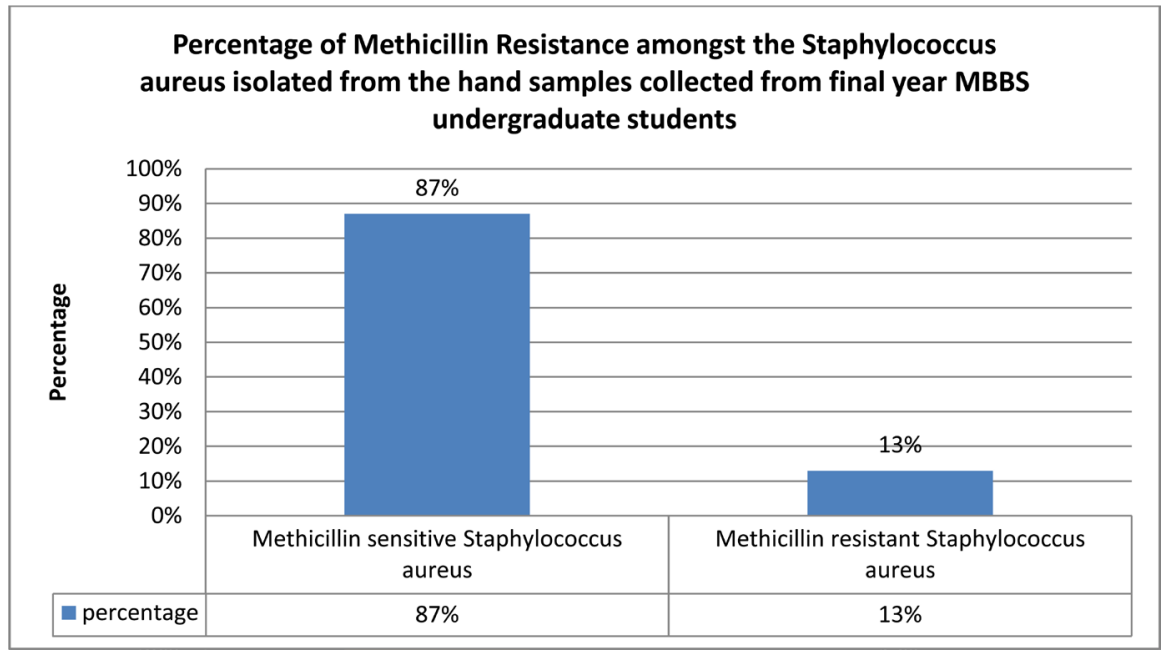

Figure 4. Percentage of Methicillin Resistance amongst the Staphylococcus aureus isolated from the hand samples collected from undergraduate final year medical students.

\section{Discussion}

The present study is about final year MBBS undergraduate medical students who are regularly attending the wards, ICUs, OTs, etc. as a part of their clinical teaching curriculum. The study shows that these students are a strong factor that may contribute for transmission of hospital acquired infection; as the bacterial isolates from their hands showed growth significant pathogens like Methicillin resistant Staphylococcus aureus, Staphylococcal strains with Inducible Clindamycin resistance, etc. In a study by Sowndarya Visalachy et al. [5], they had 42.7\% bacterial isolates (out of 327 samples) amongst which Methicillin Resistant Staphylococcus aureus were 1\%, compared to the present study where growth rate is almost $37 \%$ and Methicllin resistance is $12.5 \%$. High MRSA in the present study partially may be due to less sample size as compared to the above study. The present study had no isolation of Vancomycin resistant Enterococci, Carbapenem resistant Acinetobacter or Clostridium difficile unlike a study by Morgan DJ et al. [6] [7]. These students are potential sources for infection spread in health care settings which needs addressing specially by infection control committee. Training of MBBS students should be imparted on a regular basis to curtail such spread.

\section{References}

[1] Maheshwari, V., Kaore, N.C.M., Ramani, V.K., Gupta, S.K., Borle, A., et al. (2014) A Study to Asses Knowledge and Attitude Regarding Hand Hygiene amongst Residents and Nursing Staff in a Teritiary Care Setting of Bhopal City. Journal of Clinical and Diagnostic Research, 8, DC04-07.

[2] Shanthi, M. and Uma, S. (2009) Antimicrobial Susceptibility Pattern of Methicillin Resistant Staphylococcus aureus at Sri Ramachandra Medical Centre. Sri Ramachandra Journal of Medicine, 2, 1-4.

[3] Clinical and Laboratory Standards Institute (2015) Performance Standards for Antimicrobial Susceptibility Testing; 21th Informational Supplement (M100-S25). 
Clinicaland Laboratory Standards Institute, Wayne.

[4] Acharya, T. (2013) Inducible Clindamycin Resistance (D Test): Principle, Procedure and Interpretation.

https://microbeonline.com/inducible-clindamycin-resistance-d-test-principle-proce dure-and-interpretation/

[5] Sowndarya, V., et al. (2016) Carriage of Multidrug Resistant Bacteria on Frequently Contacted Surfaces and Hands of Health Care Workers. Journal of Clinical and Diagnostic Research : JCDR, 10, DC18-DC20.

[6] Su, C.H., Wang, J.T., Hsiung, C.A., Chien, L.J., Chi, C.L., et al. (2012) Increase of Carbapenem Resistant Acinetobacter baumanii Infection in Acute Care Hospitals in Taiwan: Association with Hospital Antimicrobial Usage. PLOS ONE, 7, e37788. https://doi.org/10.1371/journal.pone.0037788

[7] Morgan, D.J., Rogawski, E., Thom, K.A., et al. (2012) Transfer of Multidrug-Resistant Bacteria to Healthcare Workers' Gloves and Gowns after Patient Contact Increases with Environmental Contamination. Critical Care Medicine, 40, 1045-1051. https://doi.org/10.1097/CCM.0b013e31823bc7c8

Submit or recommend next manuscript to SCIRP and we will provide best service for you:

Accepting pre-submission inquiries through Email, Facebook, LinkedIn, Twitter, etc. A wide selection of journals (inclusive of 9 subjects, more than 200 journals)

Providing 24-hour high-quality service

User-friendly online submission system

Fair and swift peer-review system

Efficient typesetting and proofreading procedure

Display of the result of downloads and visits, as well as the number of cited articles

Maximum dissemination of your research work

Submit your manuscript at: http://papersubmission.scirp.org/

Or contact aim@scirp.org 